\title{
EP Tender: enabling to drive $98 \%$ Electric, at the same TCO and convenience as $100 \%$ ICE
}

\author{
Jean-Baptiste Segard, \\ EP Tender, 22 rue Gustave Eiffel F- 78300 Poissy France, jean-baptiste.segard@eptender.com
}

\begin{abstract}
Summary
Are electric vehicles capable of long distance trips? Yes, but with major sacrifice: either recharge several times en route, with a trip which takes about twice the time of an ICE vehicle, or make a significant capital investment in a large battery and vehicle. Not surprisingly both options are a major hindrance to wide EV dissemination.

Developing range extending services for Electric vehicles via energy modules is an attractive option. It resolves the above conundrum by providing peak range at a marginal cost which is commensurate to the marginal usage: peak range is required only $2 \%$ of the time! [1] [2]
\end{abstract}

\section{Introduction}

Various technical solutions are emerging like enhanced batteries or plug-in hybrid (PHEV). But the public considers the marginal use versus the marginal cost: peak range usage is only $2 \%$ of the time, whereas on board energy storage for peak usage increases significantly the vehicle's cost, and reduces its payload. Long range EVs and PHEV are thus restricted to the premium car segment.

As a result, for EVs to gain significant market share against ICE vehicles, we need to align marginal cost to marginal use.

A disruptive approach is being proposed by EP Tender [3] and our colleagues of Nomadic Power [4] : mobile energy modules, attached occasionally to the $\mathrm{EV}$, and providing the energy capacity required for peak usage $[6]$.

$98 \%$ of time

(360 days)

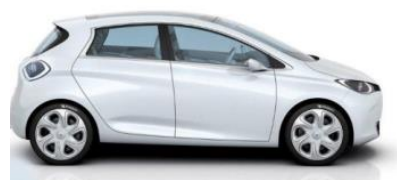

$2 \%$ of time

(6 days)

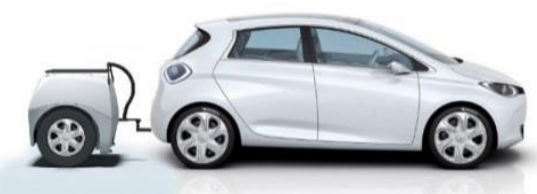

A parallel can be made with mobile phones: In consumer electronics, cost has been optimized with batteries that provide power only for typical usage (a typical smart phone's battery lasts a single day). For extra energy needs, external battery modules or chargers are used. Significantly, the consumer only pays for typical energy 
use. In this way cost, weight and volume is optimized for common use. Who would purchase and carry a phone with a huge battery, just for very occasional peak usage?

$98 \%$ of time

(360 days)
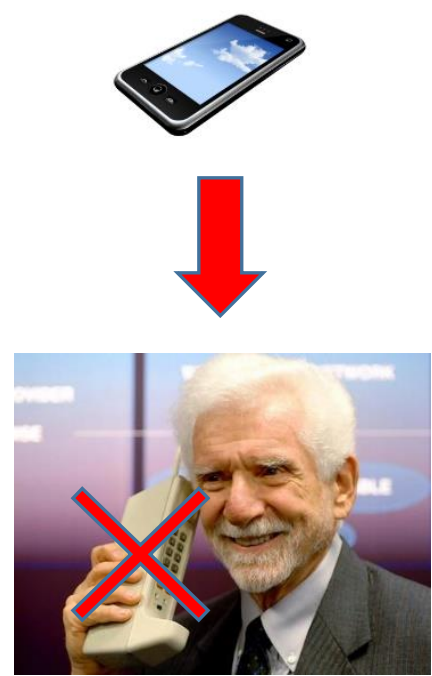

$2 \%$ of time

(6 days)
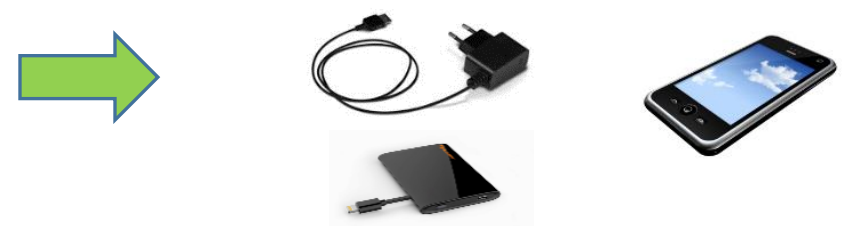

$100 \%$ of time !???

\section{User requirements}

Daily trip length distribution during the course of the year is the key determinant to EV adoption. Actual user data [2] demonstrates that an EV having a (real life) range 100 miles can satisfy all the needs of $9 \%$ of users. By using an alternate solution on 2 days only (like a range extending service), the same vehicle can satisfy $17 \%$ of users, $30 \%$ on 6 alternate solution days, and $75 \%$ on 25 days. With an EV range of 200 miles the same data is: $30 \%$ of users are fully satisfied, $49 \%$ with 2 energy modules days, $75 \%$ with 6 Tenders days, and $97 \%$ with $25 \ldots$

Although long distance trips are rare, they are made by the vast majority of users. The difficulty with batteries or on board REX is that they are a high marginal cost solution to a low marginal occurrence. Energy modules have the huge benefit to be both a convenient (see below), and low marginal cost solution. It allows the EVs to be competitive in a global and open market, and provides a huge leverage to their prospective client base (from 9\% to $30 \%$ assuming up to a mere 6 days' annual usage, plus reassurance to the $9 \%$...)

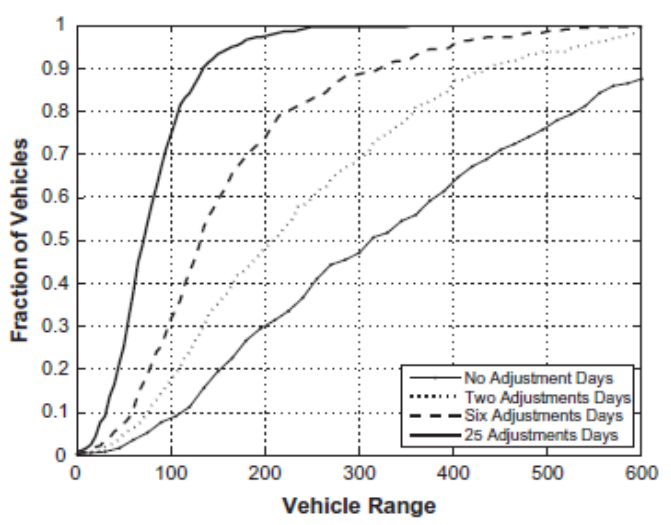

Figure1: [2] "Driving success surface by adaptation days. Fraction of the 363 vehicle fleet appropriate for varying vehicle range, with the four lines representing vehicles owners willing to make adaptions $0,2,6$ and 25 days in the year"

\section{Ease of use}

In many countries, attaching a trailer to a vehicle will require to bridge a significant cultural gap: trailers can be seen as ugly, inconvenient and hazardous! 
We fully acknowledge this challenge and have chosen to integrate these considerations as essential success factors from inception, at the design board.

\subsection{Self-steering while backing}

The steering of a trailer while backing is the most emblematic difficulty, especially when the trailer is very short, and can hardly be seen from the driver's seat.

We applied a very simple idea [7]: using classic fixed wheels when going forward, and smaller steering wheels when going backwards. This video illustrates the actual functioning of this mechanism: https://www.youtube.com/watch?v=j9gzIwc669M

We have also included backing radars to reach the same convenience as driving any car.

Manoeuvres are exactly the same with or without the Tender, except for a longer overall length (+1.3 m).

\subsection{Mechanical and electrical connection with the car}

The Tenders are connected in parallel to the EVs battery by inserting a junction box on the 400V bus. A CAN gateway is selecting messages from the vehicle and powertrain CAN networks and sends them on a dedicated CAN connection to the tender. The junction box manages the vehicle diversity through the CAN gateway software. No modifications are required on the towing vehicle, apart from mounting a tow bar, and inserting the junction box. The battery behaves as an energy buffer, and sets the tension on the HV network.

\section{Electric architecture EP Tender -Electric vehicle}

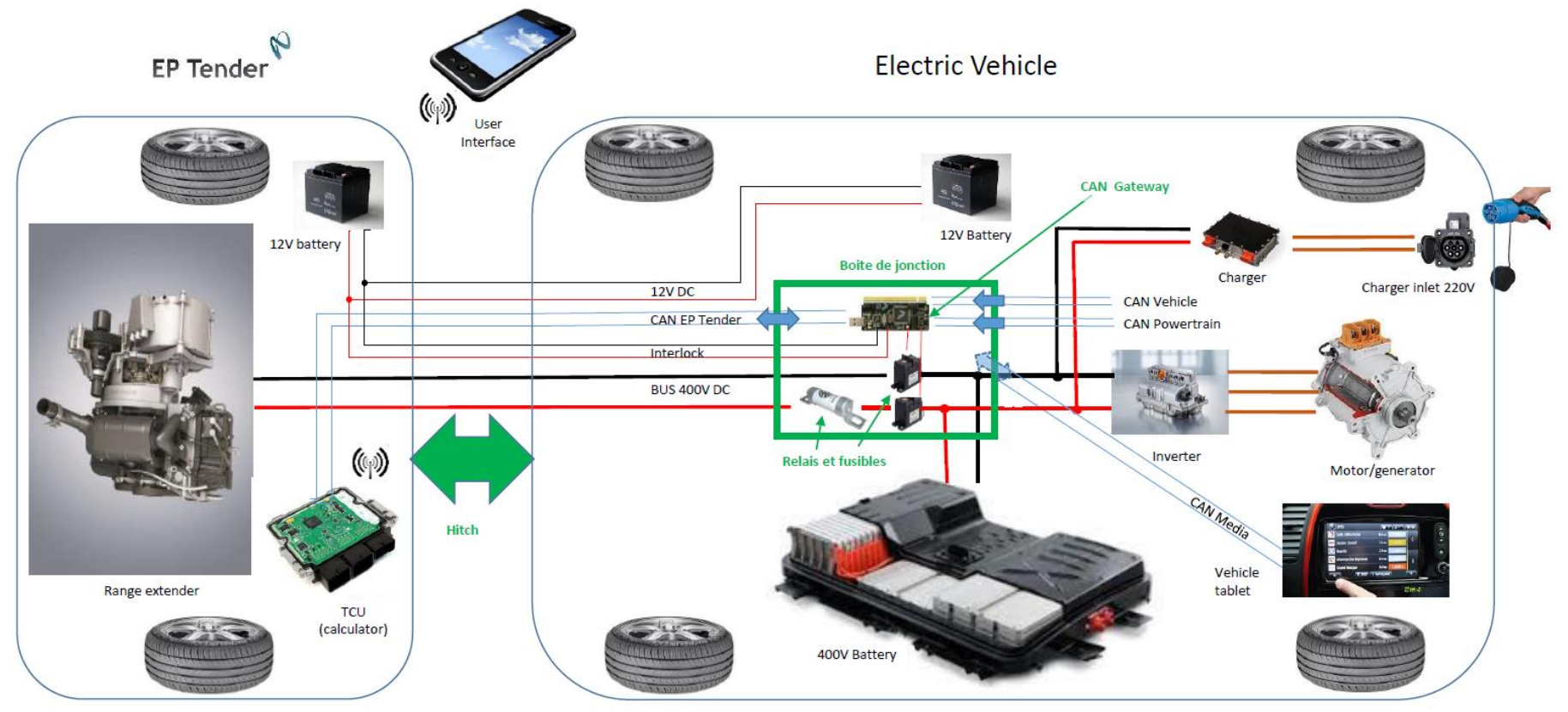

We are willing to establish a standard, which can be mounted on any EV, and accessible by any energy module, with a common mechanical and electrical interface.

\subsection{SOC target at destination and Automatic power control}

The default mode of the Tenders is to automatically start the range extender when SOC reaches $5 \%$, and to run in charge sustaining mode from that point. The users also have the ability to set a target SOC at destination, via their phone and Bluetooth. The Tender will let SOC reduce to $70 \%$, and maintain it at this 
level during the trip, until nearing destination and running again in full electric mode to deliver the target SOC required.

Over time, we will enhance this very simple approach with more sophistication, in cooperation with academic researchers [16], in order to optimise the energy management system .

The Tender is informed at all times of the max charging capability of the battery, as well as HV tension and battery current. Whenever required by regenerative braking, the range extender's power is adjusted, or cut in order to remain within the battery limits set by the BMS.

\section{Safety of operation}

Trailers can be a hazard! If modularity is to become a usual solution during long distance trips, we have to demonstrate a strong resilience to unexpected driving circumstances.

\subsection{Fuel tank integrity in a crash}

We have made crash test simulations under the FMVSS 301 US norm. The EV \& Tender are hit from the rear by a $1400 \mathrm{~kg}$ vehicle, at a speed of $80 \mathrm{~km} / \mathrm{h}$ and a $70 \%$ overlap. The results are very positive:

- The fuel tank's integrity remains entire: it is not crushed and not punctured by any part. A real crash test should demonstrate no fuel leakage, as required in this test.

- The Tender absorbs $31 \%$ of the energy absorbed by the vehicles during the crash, thus reducing by $31 \%$ the effect of the impact on both the towing and the impacting vehicles

It is very interesting to observe that the Tender acts de facto as a crash box, partially shielding the passengers of both vehicles from the consequences of such crash!

\subsection{Dynamic behaviour}

Another key element is the dynamic stability of the EV when a Tender is attached. We had the moose test (ISO 3888-2) performed, with a Renault Zoe and EP Tender. It passed the test at a speed of $104 \mathrm{~km} / \mathrm{h}$ on the road test (below), and $58 \mathrm{~km} / \mathrm{h}$ on the urban test (shorter distances), without disturbing the car or losing the Tender.

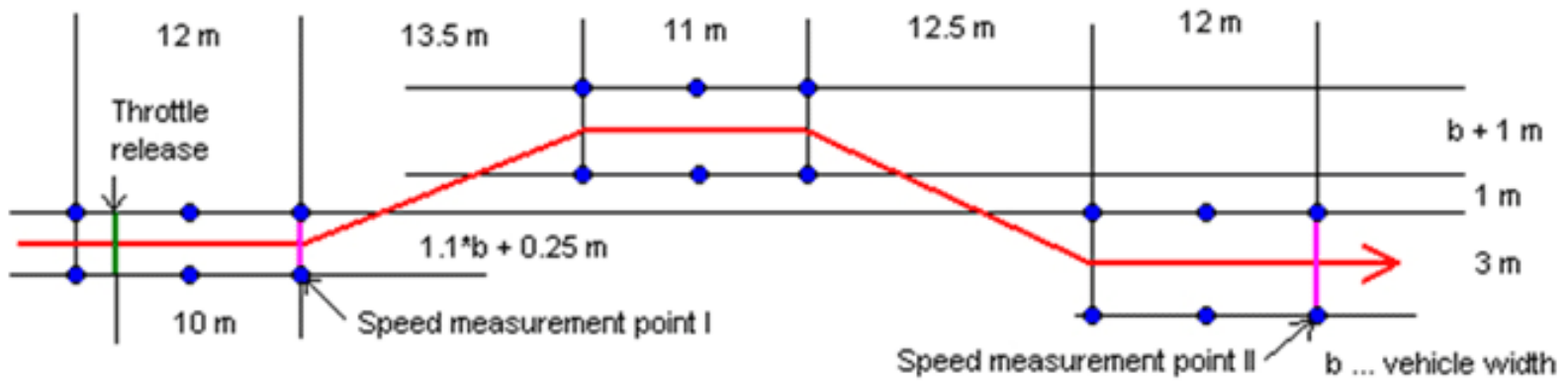

We will continue working on improving this already pretty good dynamic behaviour, by tuning the parameters of the suspension and tyres and moving further that limit.

\section{Accessibility and TCO}

The last condition for public acceptance is the accessibility as and when needed, and of course a competitive TCO.

\subsection{Tender'Lib rental network}

Users will be able to book the Tenders, as well as the dropping point, in advance of their trip. The distance from one rental point to the other will be $50 \mathrm{~km}$. Large cities will have rental points at the crossing of the main "ring road" (example of the M25 in London) and radiating motorways. Smaller cities will have rental points at the main local commercial centre (s) on the city periphery.

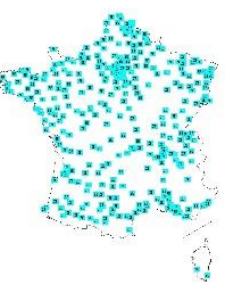

Tender'Lib example in France 
The Tenders will carry communication modules, with GPS, GPRS, Accelerometers and NFC card readers. The management of the rental network is entirely wireless. As a result, the rental points require no electric connections or civil works, making them easy and quite cheap to deploy.

\subsection{Cost}

Thanks to on demand rental, the cost is pay per use model. If the user goes out for 2 week holidays, he will only rent a Tender on the way out and another one on the way back. The annual budget will remain well below the rental of another car, or the ownership of a second car.

\subsection{Fuel consumption}

Fuel consumption is zero $98 \%$ of the time! Only $2 \%$ of the trips (say $10 \%$ of distance) will burn fuel.

The efficiency of the dual conversion mechanical-electrical-mechanical will be $80 \%$ at most, plus the cost of cold weather (up to $10-15 \%$ ), and the cost of towing a light trailer (3\% est.). The aero drag is negligible, as the trailer is lower and narrower than the car.

On the contrary, on a 500km trip, the battery will provide $20 \%$ to $40 \%$ of fuel saving (assuming an actual range of $100 \mathrm{~km}$ to $200 \mathrm{~km}$ ), and there will be around 5\% saving on regenerative braking. The net result on $500 \mathrm{~km}$ will range from $+20 \%$ to flat. Shorter trips will be in favour of EP Tender, while on longer trips the driver will likely recharge during a meal break.

We expect the annual consumption of occasional users to be 1/10th of the annual consumption of an ICE vehicle. We plan to measure the average annual fuel consumption of our fleet of users, and publish that figure, as well as providing the individual data to each client.

\section{Marketing research}

We have made detailed marketing research about EP Tender's user acceptance. The main outcome is from the research we made in 2014 with TNS Sofres on 802 people. 3.7\% of car buyers declare they are certain to purchase an EV if EP Tender is available, 95\% of them will prefer a car which is available with a hitch option, and 50\% mount the hitch and use EP Tender. In addition, $21 \%$ of existing EV owners will certainly use EP Tender.

In total the target market share is $2 \%$ of car buyers. This is nothing but a niche market, but this is a very valid business proposition given the size of the global automotive market!

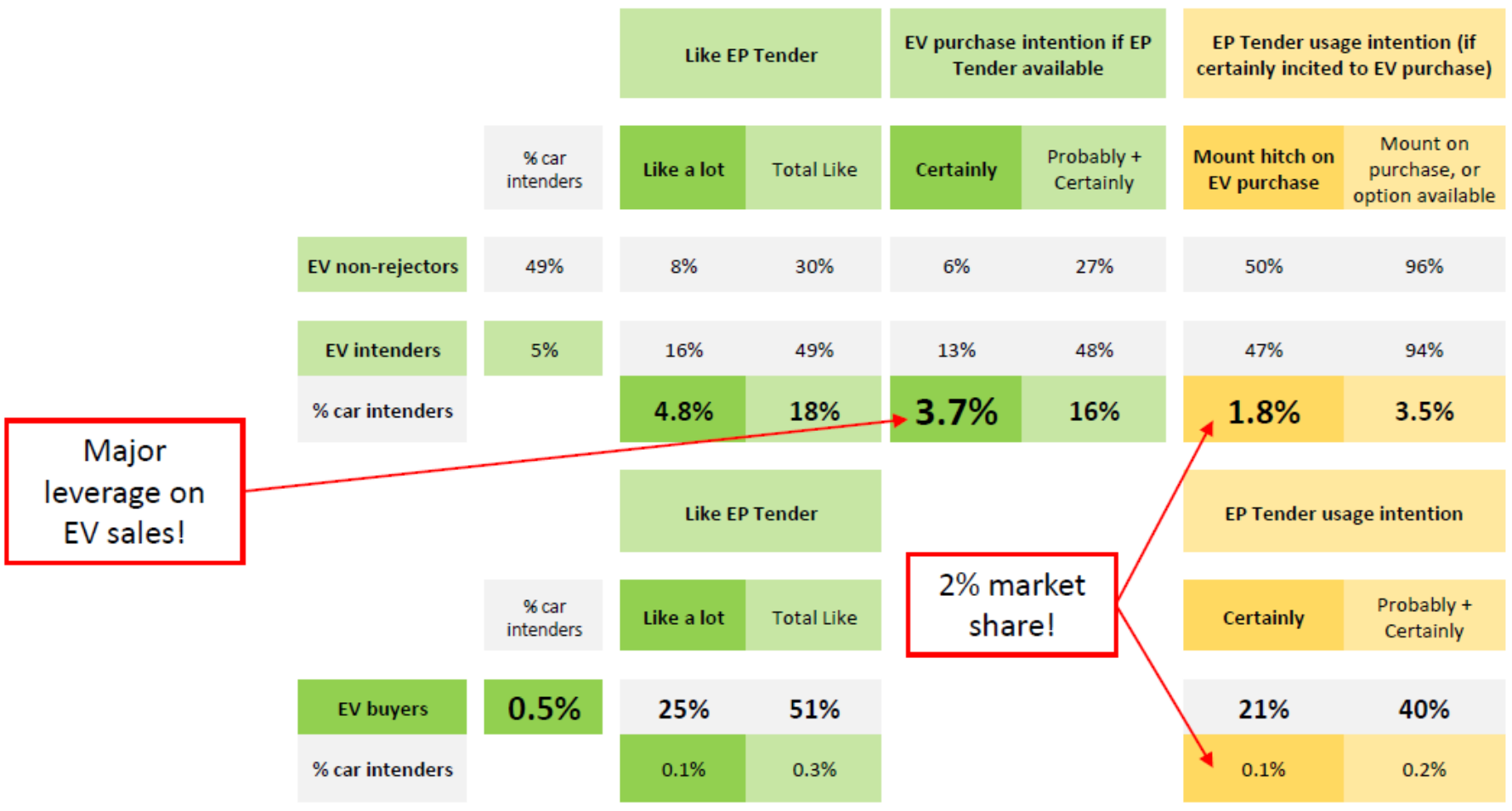


According to these figures, the EV penetration would be increased by a factor of 4 , assuming $1 \%$ at the moment.

\section{Alternate solutions}

Tom Gage at AC Propulsion has developed an early demonstrator of the future Tesla Roadster and its powertrain, as well as a very interesting self-steering mobile range extender, from 1992 to 2001 [8].

Better Place has failed due to over expensive infrastructure and high constraints on vehicle/battery integration. Sadly they have sunk 850 M USD [9]. But there was some truth in their understanding of the range and marginal cost requirements. This unfortunately has left some scars and added cautiousness on the side of car makers. Tesla has made a recent implementation, but it appears to be for California ZEV tax credit optimization, not for real business perspective [10]. This concept is now abandoned by Tesla as well.

Plug-in Hybrid Electric Vehicles: quite a few new products (A3, Golf GTE, BMW i3, New Volt), and many high tech range extender prototypes with equipment makers (AVL, KSPG, LotusFagor, Polaris-SwissAuto, Mahle, Obrist, etc.). The difficulty is to keep an acceptable level of cost, given the complexity involved. This is acceptable for large or premium cars, but not reasonable for smaller and affordable cars. The other significant downsides are that the full electric range tends to be lower than a full EV (Golf GTE $=40 \mathrm{~km}$ effective electric range [11]), or the gasoline range is less than a classic ICE (BMW i3 = 91 fuel tank), and the trunk gets smaller in order to accommodate for all the technology (only 2701 in the Golf GTE vs 3701 in the e-Golf and 2251 in the BMW i3).

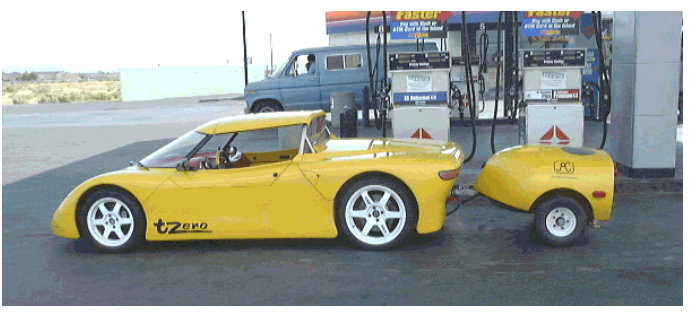

http://www.tzev.com/1992_1995_2001_acp_rxt-g_.html
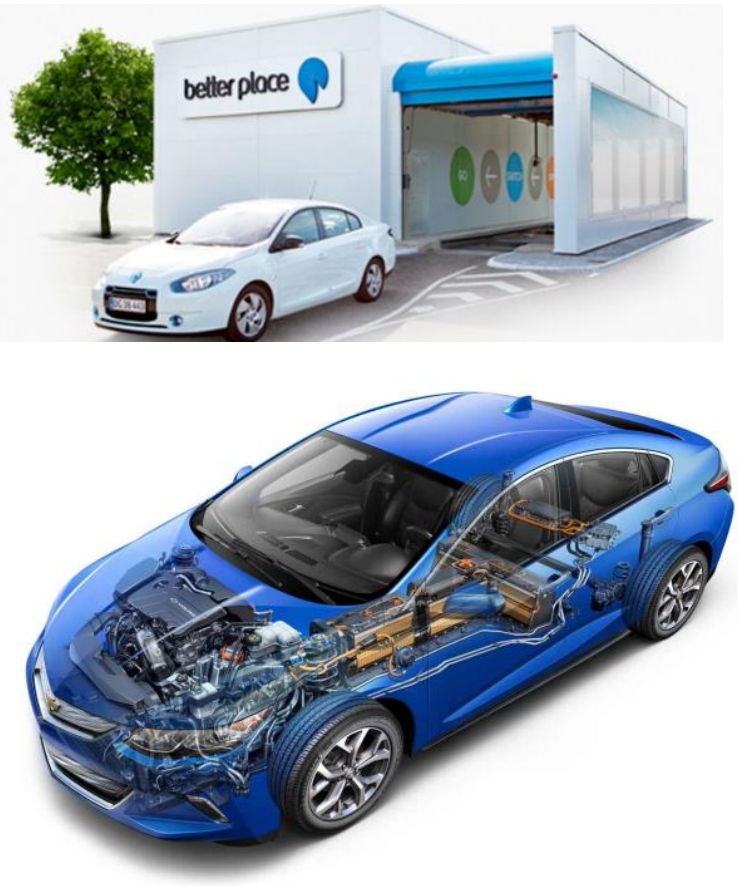

Chevrolet Volt

Very large batteries: Tesla Model S is probably the best car in the world, and loved by affluent enthusiasts. But such a large, heavy and expensive car is not ideal in towns, and is not a good cruiser, requiring to stop 35 ' every $225 \mathrm{~km}$ (assuming driving at $130 \mathrm{~km} / \mathrm{h}$ and $80 \%$ battery charge on Supercharger). Recent examples of cross continental trips in the US show that total trip duration is just above $30 \%$ higher than the same trip with an ICE. Recent academic work from Oak Ridge National Laboratory [12], confirms that most users are better-off with 100 miles range. Model S and the new Model X are anyhow a great symbol helping to enhance the credibility of EVs.

Well before reaching $30 \% \mathrm{EV}$ penetration, the governments will have cut their subsidies. In order for EVs to be cost competitive with ICE vehicles, their cost will have to decrease significantly, and it is very unlikely this could be achieved by carrying large batteries for peak usage...

It is also very unlikely that the charging stations could deliver as much car-miles as a petrol service stations with any significant EV market share: a fuel pump is delivering $7 \mathrm{MW}$ power to the fuel tank, which is $2 \mathrm{MW}$ usable to run the wheels assuming $28 \%$ efficiency. A service station

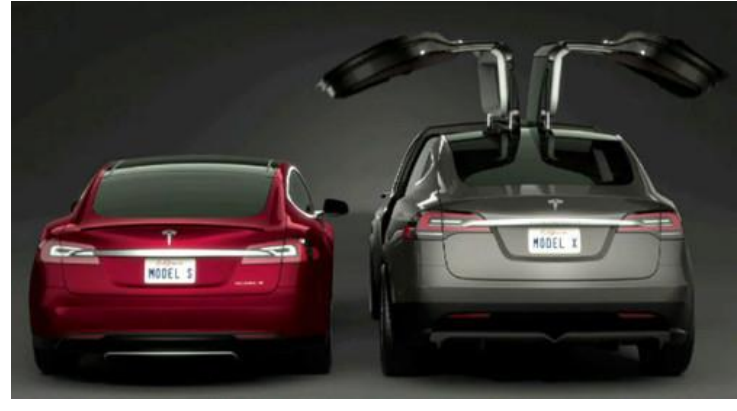

Tesla Model S and Model X 
having 10 pumps equates to $20 \mathrm{MW}$ power for the same number of car-miles, a power line of $60 \mathrm{kV}$, and has a major impact on the Grid at peak times!

EVs are a formidable match with renewable (and intermittent) energy production because they can charge during troughs of demand, and avoid peak demand charging (if not feeding back the network). Fast charging masses of EVs on peak travel would simply defeat that point, regardless of cost and all technical considerations.

It looks like Elon Musk is starting to give consideration to the battery on trailer option, as he mentioned in this interview (between 15'50" and 17'32" ): https://www.youtube.com/watch?v=Off7830aMp0

Fuel cells: this technology remains very expensive in itself, as well as requiring $\mathrm{H}_{2}$ distribution infrastructure. There is also the debate on how to manufacture clean $\mathrm{H}_{2}$ at acceptable efficiency. It will take years to emerge as a viable stand-alone business, as expensive and scarce infrastructure has to be used by expensive and scarce vehicles...

Synthetic fuel: possibly the best of all solutions could be the production of synthetic fuel from solar energy, hydrogen and carbon capture. Energy density and ease of storage would no longer be an issue, but this still remains highly hypothetical.

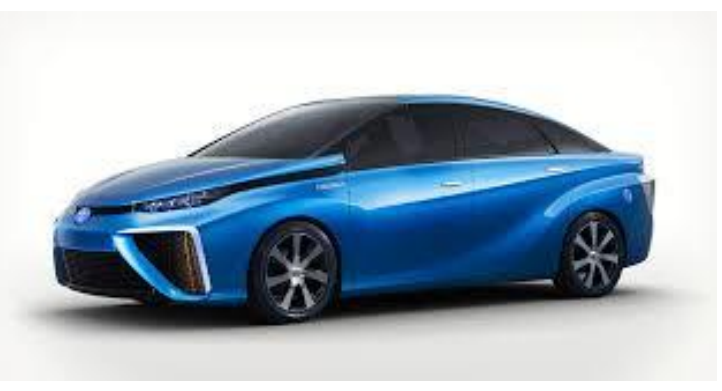

Toyota Mirai

EV as main car + ICE car rental: this solution is perfect in the context of multimodal trips. But costs are higher, and door to door trips are often more convenient than having to fetch a vehicle at the car rental (unless as a complement to plane or train). EP Tender's research [13] shows that only $11.5 \%$ of EV owners prefer this solution.

The fundamental benefit of designing a car for optimal daily usage and adding on demand an energy module for occasional long distance will remain as long as the marginal cost and weight of a larger battery remains a multiple of a larger fuel tank [14], as well as the time for filling it.

\section{Business model}

A good technology and product is nothing without a good business model. Pricing power, distribution and growth potential are the key determinants.

\section{Pricing power}

The pricing power of energy modules is quite strong due to:

- High client value (unlimited range)

- Sticky clients and recurring revenues (once the EV is equipped with the hitch it will likely remain client for $10-15$ years)

- Intellectual property safeguards key feature (self steering \& fuel tank safety) and helps maintaining healthy margins

\section{Distribution}

Car dealers will play an essential role in the distribution and mounting of the tow bars on EVs and the promotion of energy modules to prospective EV clients, which will facilitate EV adoption as demonstrated above. The client acquisition cost will then reside mostly on the car maker's side.

\section{Growth}

- This business model is very scalable once the basic structures is in place.

- Costs are mostly variable: building the energy modules, and operating them. 
- The market is global, and very large.

- Expected growth for EVs is well into double digits for many years to come.

The combination of such positive features in a single business model is quite rare. We have chosen to aim high and take risks, but if our execution is right, the energy modules businesses could be highly successful.

\section{Life Cycle Impact}

We expect the life cycle impact of EVs to be much better trough a modular approach than by trying to fit the car with peak range energy storage by:

$\circ$ sharing the range extender, instead of carrying it in every car all year long

- keeping the battery at a reasonable size, satisfying $98 \%$ of usage

- slow battery charging at night, or during demand troughs

Formal academic research has been mandated to the Vrije University in Brussels in order to verify and quantify these assumptions.

\section{Analysis of a long distance trip}

We have exhibited EP Tender at the Geneva motor show in March 2016. Quite naturally we drove the demo car and the Tender on the motorway. The char below illustrates the $555 \mathrm{~km}$ trip from Geneva to Paris.

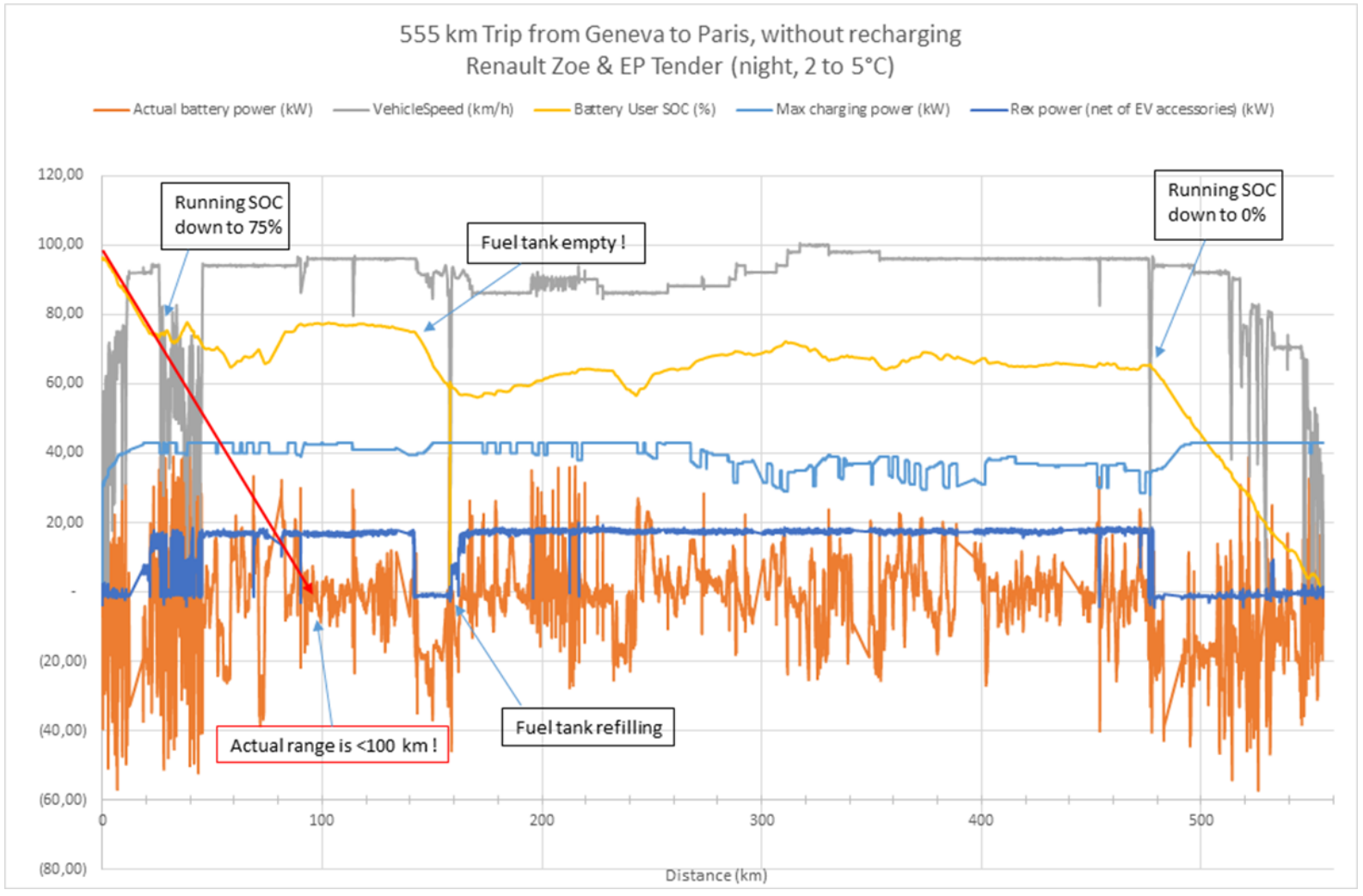

The trip has been made at night, in one go, with a relatively cold weather (accessories were taking 1 to 1.5 $\mathrm{kW}$ ). Without a Tender, we would have had to stop 7 times, every $75 \mathrm{~km}$ to recharge up to $80 \%$, assuming fast charging stations positioned to perfection. In other words, such trip would not have been done otherwise. The chart illustrates the initial decrease of SOC to $75 \%$ in full electric mode, the charge sustaining mode around $70 \%$, and the last leg in full electric mode to reach $0 \%$ SOC at destination. The fuel tank wasn't full at departure and had to be refilled at $\mathrm{km} 180$. 


\section{Specifications of the preseries version}

- Weight: $250 \mathrm{~kg}$

- L 1300, W 1200, H 900

- ICE: Tata Nano, 624 cc, 2 cylinder

- Generator : NSM, permanent magnet synchroneous

- Windings : $2 * 22$ poles, $360 \mathrm{~V} 4500 \mathrm{rpm}$ with rectifier bridge (battery sets the tension, hence the speed)

- 2 electromechanical speed: nominal $4500 \mathrm{rpm} / 2250 \mathrm{rpm}$ (windings in parallel / series)

- Net electric power: up to $20 \mathrm{~kW}$ at $4700 \mathrm{rpm}$

- Fuel Tank: 35 litres

- Fuel consumption: to be calibrated. Target is to reach $300 \mathrm{~g} / \mathrm{kWh}$

- Energy production target: $85 \mathrm{kWh}$

- Self steering when backing

- Self locking hitch with automatic plug connection

- Car sharing module with GPS, GPRS, accelerometer, NFC card reader

- Luggage rack

\section{$12 \mathrm{H} 2020$ progress report}

EP Tender is proud to benefit from H2020 SME phase 2 support [3], as well as our competitor Nomadic Power [4][6]. Our project consists at building a preseries of 8 Tenders, and test them on the field with 50 vehicles between Paris and Rouen, as well as make demonstrations in China and North

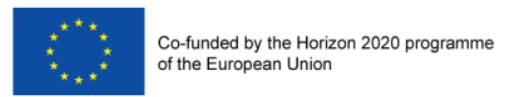
America, and some other European countries.

The field test will start during the course of the summer 2016, with up to 50 EVs, from fleets (ERDF, city of Rouen, a small transport company) and private individuals. From this experience, we will measure user satisfaction and evaluate the commercial potential of the network once deployed. We are also developing quantitative models for simulating demand and optimizing our fleet of Tenders. The field test will strengthen our arguments, reinforce public awareness, and quite likely generate demand from existing and prospective EV buyers.

We are also planning to make demonstrations in the US, with an initial base in Hickman (CA), where there is a community of 58 Nissan Leaf in a radius of 5 miles. We will initially equip one car, and in 2017 expand into a field test.

We found significant interest in China as well, with two small OEM ready to test EP Tender on their vehicles, and some good leads with municipalities and fleet managers.

The vehicle homologation process will likely create delays and execution risk, but we trust that once the evidence of the soundness of the concept is established, the regulatory authorities will be more and more supportive. 


\section{Fuel Cell}

Slow charging of a battery from the Grid is the best possible energy efficiency proposition. We have demonstrated above that modularity is a major enabler of $\mathrm{EV}$ dissemination, as it allows accessing to long distance range at an acceptable marginal cost.

Fuel cells are seen as a credible solution for long range vehicles, but they suffer from the significant costs of deploying $\mathrm{H} 2$ distribution infrastructure, and of the vehicles themselves. These are hard to overcome barriers to entry and would require massive public support.

An alternate approach is to mount the fuel cells on the Tenders, and make them available on corridors equipped with $\mathrm{H} 2$ distribution.

The results are:

- Affordable EVs are driven on slow battery charging for everyday usage (which is optimal)

- When making a long distance trip on a corridor equipped with $\mathrm{H} 2$ distribution, the user rents a fuel Cell Tender and pays only for its marginal usage.

- When making a long distance trip on a route not yet equipped with $\mathrm{H} 2$ distribution, the user rents a gasoline Tender.

- $\quad \mathrm{H} 2$ can be deployed progressively, used by affordable basic EVs, and with a viable business model, thus requiring less public support.

There is an interesting project of an 80 Day Race around the world in the course of 2018 (www.80dr.com). We would love to find partners to participate to this race with a full EV and a Fuel Cell Tender.

\section{Our vision for 2030}

Cars are clean, connected, autonomous and lean. The functional economy represents a significant and growing percentage of GDP.

The typical range of a car satisfies $98 \%$ of its use cases with its on board battery. The Tenders are booked automatically by the EV's navigation system, and join automatically the $\mathrm{EV}$ when it reaches the motorway for a long distance trip.

The cars (the passenger modules!) are optimized for theirs daily usage, and are supplemented by the most suitable energy module given the infrastructure available on a long distance trip (grid charging, H2, inductive road [23], bio/synthetic fuel).

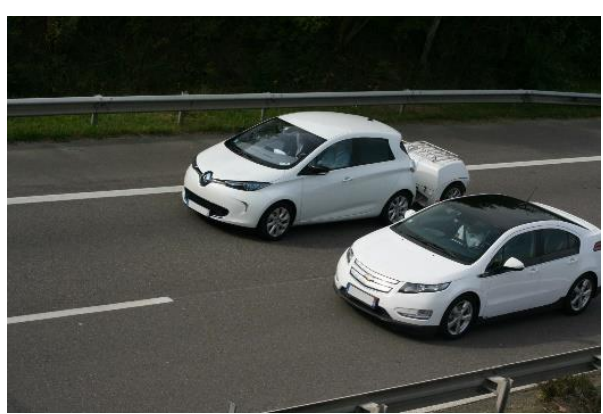

The life cycle environmental impact of road transport is minimized thanks to the motorway commuting of energy modules, providing peak energy demands to EVs.

The cars will be indifferently owned, or shared. The energy modules will be shared. Range extending is a service. 


\section{Conclusion}

EP Tender is contributing to solving the range issue of EVs destined to the general public, in a convenient and affordable way, with great care put on safety.

This innovation should significantly enhance the rate of growth of EV dissemination and prove fully disruptive.

Car makers and the stakeholders of soft mobility will benefit from supporting this concept of range extending service for EVs.

\section{References}

[1] Long distance trips in France:

http://www.statistiques.developpementdurable.gouv.fr/fileadmin/documents/Produ its_editoriaux/Publications/Chiffres_et_stati stiques/2014/chiffres-stats590-mobilitelongue-distance-des-francais-en-2013decembre2014.pdf , page 2

[2] Electric vehicles: How much range is required for a day's driving? Transportation Research Part C 19 (2011) 1171-1184; Nathaniel S. Pearre, Willett Kempton, Randall L. Guensler, Vetri V. Elango

[3] EP Tender's H2020 abstract

https://ec.europa.eu/easme/en/sme/5287/inn ovative-range-extending-service-electricvehicles-ev-based-modular-range-extender

[4] Nomadic Power's H2020 abstract

https://ec.europa.eu/easme/en/sme/5519/mo bile-energy-system-recharging-energybuffering-and-long-distance-travelling

[6] Modular energy for electric vehicles: a paradigm shifting innovation for the transport sector, EEVC European Battery, Hybrid and Fuel Cell Electric Vehicle Congress, ISSN - 0774-5036, Brussels December 2015 Jean-Baptiste Segard (EP Tender), Manfred Baumgärtner (Nomadic Power)

http://www.eptender.com/SiteAssets/EEVC
\%20paper\%20EP\%20Tender\%20$\% 20$ Nomadic\%20Power.pdf

[7] ROAD TRAILER WITH ORIENTABLE SECONDARY WHEELSET https://patentscope.wipo.int/search/en/detail.js f?docId=WO2013132468\&amp;recNum $=1 \&$ amp;tab=PCTDocuments\&amp;maxRec $=27$

\&amp;office=\&amp;prevFilter=\&amp;sortOp tion=Pub+Date+Desc\&amp;queryString=FP:( segard)

[8] Low-Emission Range Extender for Electric Vehicles Thomas B. Gage AC Propulsion Inc. Michael A. Bogdanoff South Coast Air Quality Management District

http://www.tzev.com/files/rxtg_acp_white_paper_range_extending_trailers. pdf

[9] Better Place's Failure

http://www.wsj.com/articles/SB10001424127 $\underline{887323855804578507263247107312}$

[10] Tesla Battery Swapping: Useful Service Or Minimal Effort For Extra Income?

http://www.greencarreports.com/news/10972 14 tesla-battery-swapping-useful-service-orminimal-effort-for-extra-income

[11] VW Golf GTE tested by Auto Plus ! http://news.autoplus.fr/news/1491103/Essaivid\%C3\%A9o-hybride-rechargeableVolkswagen-Golf-GTE 
[12] You're Better Off Buying 100-Mile Electric Cars, Report Says; Shoppers May Disagree

http://www.greencarreports.com/news/1093 941_youre-better-off-buying-100-mileelectric-cars-report-says-shoppers-maydisagree

[13] EP Tender market research, p9

https://www.dropbox.com/s/eubmu5r0nfs4y h3/EP\%20Tender\%20market\%20research.p $\underline{\mathrm{df} ? \mathrm{dl}=0}$

[14] Jaguar Land Rover. Hybrid electric vehicle batteries: getting the most out of cell chemistry through engineering

http://futurepowertrains.co.uk/2015/assets/d ownloads/presentations/chris-lyness.pdf

[15] Powering electric vehicles on England's major roads, Transport Research Laboratory (TRL), page 63

http://assets.highways.gov.uk/specialistinformation/knowledge-compendium/20142015/Feasibility+study+Powering+electric+ vehicles+on+Englands+major+roads.pdf

[16] Energy Management System for an Electric Vehicle with rental Range Extender: a least costly approach, To be published in IEEE Transactions on Intelligent Transportation Systems. Jacopo Guanetti, Simone formentin, and Sergio Savaresi, Politecnico di Milano

\section{Author}

Jean-Baptiste Segard graduated from the Swiss Federal Institute of Technology in Lausanne (EPFL). He received the Maillefert award for research and creativity. He founded EP Tender in 2012 from his own frustration of willing to purchase an EV, but having to renounce due to rare occasional long distance trips (he now drives an EV!). He was previously a senior executive in the asset management industry.

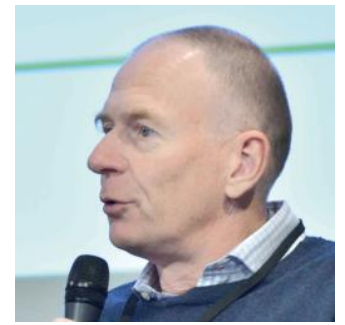

